\title{
Patients as Active Partners in Research - a Fashionable Phrase or a Fundamental Paradigm Shift?
}

\author{
Frauke Musial \\ National Research Center in Complementary and Alternative Medicine (NAFKAM), Department of Community Medicine, UiT The Arctic \\ University of Norway, Troms $\varnothing$, Norway
}

Over the last decade, the patient's role in their treatment has changed dramatically. The availability of medical information, in particular through the internet, has led to a situation where patients are increasingly taking over the role of decision makers. Doctors and caregivers are suddenly confronted with informed and engaged patients, who claim to have a role in their treatment plan and choices but who at the same time are also willing to take over responsibility for the handling of their health and illnesses.

In many situations, such as after a devastating diagnosis, patients not only have to come to terms with a chronic illness, they have to make decisions for or against therapeutic interventions. This is sometimes particularly challenging in situations, where the ability to make informed choices is impaired, e.g. in case of acute stroke, where it will most likely be up to the nearest to find the right choice. There, the option for choice may often be limited, nonetheless, the ethical issue of participation remains and there is increasing awareness in modern healthcare and in many societies that participation and choice in healthcare and treatment are values in itself that are desirable.

The possibility to participate in treatment and the ability to 'do something for myself are also reasons why patients choose therapeutic interventions out of the spectrum of complementary and alternative medicine (CAM). This holds true for patients with minor chronic health complaints as well as serious and life-threatening diseases, such as multiple sclerosis or cancer [1-3]. Therefore, patient participation is a topic with particular relevance for CAM.

Norway is most likely one of the countries in the Western world that has taken patient participation most serious. In the 'coordination reform', which is currently gradually implemented $[4,5]$, it is claimed that the individual patient shall participate in their own preventive, treatment, rehabilitation, and care programs; and that patients and user organizations shall moreover be involved on a systemic level, i.e. in the development and configuration of systems and overall decisions that build the framework and conditions for how the services are provided to the individual patient [4, chapter 5: Patient Role and Patient Care].

The principal understanding which formed the basis for such a fundamental claim is that 'patients who participate in the planning and monitoring of their health care, are better able to mobilize their own resources. This can improve the prognosis for good results. There exist strong and competent user and patient organizations who want to influence the services' development and to participate on behalf of patients. User involvement adds thus value to health and care' [4, chapter 5.3: Patient's Role in Health Care - Relationship to Participation].

And Norway is right in this! All evidence shows that feelings of helplessness and depression have detrimental effects on the course of a disease. Further, it has been shown in many studies that patients feel a need for self-help and participation in therapy. Therefore, all evidence suggests that an active, informed patient as a partner in therapy is not only a development that we as a society want to promote on a more or less conscious level; patients taking an active role in their disease management may rather be part of the healing process, already. And there is evidence that this is why many patients turn to CAM - a medicine which usually requires an active participation of the patient.

One of the consequences of this fundamental change in the principal understanding in what will determine good healthcare is the fact that there is now also a demand for patient participation in clinical research in Norway. Patient participation on the individual and system level in all phases of planning and conducting clinical trials or health services research is now a must for clinical research in Norway.

One may think that Norway is particularly radical in its approach; however the trend for more patient participation, not only in treatment but also in research, is a paradigm shift that is prevalent, which is good! This paradigm shift will help us researchers to make our studies more relevant. It is the patients and their caregivers, families, and nearest who know best what is important to them.

\section{KARGER}

Fax +497614520714
(๑) 2015 S. Karger GmbH, Freiburg

$1661-4119 / 15 / 0224-0224 \$ 39.50 / 0$
Frauke Musial, PhD

National Research Center in Complementary and Alternative Medicine (NAFKAM)

Department of Community Medicine

UiT The Arctic University of Norway, 9037 Tromsø, Norway

frauke.musial@uit.no 
I myself am a dedicated supporter of the use of biomarkers in CAM research, however, I am well aware that it will be the change in subjective well-being that might make the therapy under investigation relevant for potential users, and not the change in a biomarker, may it be as dramatic and biologically relevant as it can be.

Clinical researchers have long been aware of the issue which is mirrored in the shift over the last decades from pure research on biomarkers towards primary outcomes, such as quality of life. However, the demand that lies in this fundamental paradigm shift reaches much further: Patients now have a right to actively be involved in planning and conduct of clinical research, and this calls for new paradigms and new methodological approaches. Personally, I believe that the methodology is available and I find it interesting to see how research and maybe even research results may change under this new 'directive'.

Reference panels who will include possible interest groups and who are involved in all phases of a trial will be a resource for input, offering a basis for discussion for the research teams. Multimethodological approaches combining quantitative and qualitative methodology are nearly a must, already. Qualitative research can precede a quantitative study and can, e.g., help to identify ethical issues. The pre-discussion of ethical and relevance issues with patients and their nearest will help to find solutions for potential ethical challenges of a study (e.g., blinding, randomization, etc.) and can as such increase adherence to and compliance with a trial to a large extend.

Last but not least, clinical research involving patients should always be seen as a contract between partners, striving to improve healthcare and thus creating an added value for society. We as clinical researchers value the patients who participate in our studies, because without them we are principally unable to conduct our research! The role of patients in research is fundamentally valued, e.g., in the guidelines used by the ethics committees in Germany [6]. However, the role of patients as it is claimed now represents a new dimension of participation. Patients are now active partners in the development of research designs, they are a great resource for us as researches, and we should welcome them to the team!

\section{References}

1 Salamonsen A, Launsø L, Kruse T, Eriksen SH: Understanding unexpected courses of multiple sclerosis among patients using complementary and alternative medicine. A travel from recipient to explorer. Int J Qual Stud Health Well-being 2010;5:5032.

2 Sirois FM: Motivations for consulting complementary and alternative medicine practitioners: a comparison of consumers from 1997-8 and 2005. BMC Complement Altern Med 2008;29:16.

3 Sirois FM: Provider-based complementary and alternative medicine use among three chronic illness groups: associations with psychosocial factors and concurrent use of conventional health-care services. Complement Ther Med 2008;16:74-81.

4 Hanssen BH: Samhandlingsreformen. www.regjeringen.no/no/dokumenter/stmeld$n r-47-2008-2009-/ i d 567201 /$ (in Norwegian; accessed 12.08.2015).

5 Hanssen BH: A new reform of the health sector. The Coordination Reform. www. regjeringen.no/globalassets/upload/hod/portrettbilder/ekspertutvalget/bhh-ppt-trondheim-en-24-09-08.pdf (in English; accessed 12.08.2015).

6 Raspe H, Hüppe A, Strech D, Taupitz J: Empfehlungen zur Begutachtung klinischer Studien durch Ethik-Kommissionen. Köln, Deutscher Ärzte-Verlag, 2012, 7-8.

Patients as Active Partners in Research 